\title{
A DEA APPROACH FOR PERFORMANCE ASSESSMENT OF CALL CENTRE AGENTS
}

\author{
Viera Mendelová1, Petra Strnádová2
}

\footnotetext{
1 Matej Bel University in Banská Bystrica, Faculty of Economics, Department of Quantitative Methods and Information Systems, Slovakia, ORCID: 0000-0002-4622-7433, viera.mendelova@umb.sk;

2 Matej Bel University in Banská Bystrica, Faculty of Economics, Department of Language Communication in Business, Slovakia, ORCID: 0000-0002-4038-6177, petra.strnadova@umb.sk.
}

\begin{abstract}
The paper focuses on a relatively new and prospective application of the data envelopment analysis (DEA) in the employee performance assessment. In the paper, a novel DEA approach is proposed for evaluating the performance of call centre agents, based on their relative efficiency. Since call centres handle a majority of customer-company interactions, performance of call centre agents largely influences the future success or failure of a company. To ensure the quality of customer service, permanent evaluation of call centre agents' performance is essential. The proposed DEA model consisting of two input variables (wage and working time) and five output variables (quick-answer calls proportion, customer satisfaction, net first contact resolution, call quality and inbound contact handle time) has been tested on 55 call centre agents working at the call centre of one of the largest telecommunications operators in the Slovak Republic. After measuring the performance of each agent, based on the DEA models, the call centre agents' performance was evaluated in the DEA matrix format. As a result, the call centre agents were divided into four groups: Stars, Cash Cows, Question Marks and Poor Dogs. Finally, based on the proposed approach, recommendations for call centre managers on how to improve or maintain the performance of each of these groups were drawn. The proposed approach provides a practical framework for call centre managers to assess the performance of the agents, and to plan and take steps to improve the quality of call centre services.
\end{abstract}

Keywords: Performance appraisal, data envelopment analysis, call centre agents.

JEL Classification: M54, C60.

APA Style Citation: Mendelová, V., \& Strnádová, P. (2020). A DEA Approach for Performance Assessment of Call Centre Agents. E\&M Economics and Management, 23(3), 173-190. https://doi.org/10.15240/tul/001/2020-3-011

\section{Introduction}

A call centre is, in general, an organizational unit of a company, which handles a huge volume of telephone calls, especially for taking orders and providing customer service. The origins of call centres date back to the 1960s and are linked to the UK-based Birmingham Press and Mail, which installed Private Automated Business Exchanges (PABX) to have agents dealing with the customer contacts. The call centres we know today started along with the invention of the Automated Call Distributor (ACD) technology, which uses algorithms to filter through calls, and allocate the right calls to the right call centre agents, based on some pre-set rules.

As more and more companies are aware of the importance of retaining their customers, more attention is being paid to the Customer Relationship Management (CRM) system. As CRM has become the centre of companies' attention, call centres, which are at the forefront of the CRM strategy, are regarded as important communication channels between the company and its customers. It is generally believed that the attitude of the customers to the company is largely influenced by the interactions between the customers and the people in the company they get in contact with when addressing 
their needs. Therefore, the call centre agents who have a direct contact with the company's customers play the key role in determining the final impression of the company the customers get. As a result, the performance of the call centre agents has a considerable impact on the overall performance of the company. If the call centre agents fail to sufficiently understand the customers' complaints and needs, the company may bear the serious consequence of losing the customers. On the other hand, if the customers are satisfied with the call centre agents who respond to their needs promptly and properly, the company may profit from the returning customers and even the new ones, because of positive references from the existing customers. This relationship of employees' performance to the company's performance is well-documented in the literature (Katzenbach \& Smith, 1993; Kilduff et al., 2000; Higgs, 2005).

Companies should periodically assess the performance of each call centre agent, and use the information to improve the operations of their call centre. Therefore, performance appraisal (PA) of the call centre agents is an important part of the call centre management. In order to provide high quality service and to achieve customer satisfaction, call centre agents are commonly managed and monitored through a number of key performance indicators (KPIs). The evaluation of fulfilment of the individual KPIs usually requires setting the performance objectives and standards. They help to evaluate the individual KPIs by allowing for clear percentage of their fulfilment. In practice, several approaches to setting and evaluating the optimal target values for the KPIs are used. Beside the empirical or expert techniques, there is an increasingly popular option of benchmarking, i.e. comparison and identification of potential differences in the achieved results in relation to the industry competitors. The crucial problem of all these methods traditionally used in the PA of call centre agents is that aligning the high number of KPIs into a single composite indicator that covers the overall performance of a call centre agent is often quite challenging. As the pressure on call centre management to be more efficient increases, the call centre managers are forced to look for the most effective tools to evaluate call centre agent performance. It is quite essential to have such PA methods that allow for a wide range of KPIs to be taken into account and provide relevant and comprehensive results related to the performance of call centre agents.

For this reason, especially in the recent years, new modern methods based on multicriteria performance assessment have begun to emerge. The data envelopment analysis (DEA) represents one of the relatively frequently used methods for measuring technical efficiency of the decision-making units (DMUs). From the application point of view, DEA has usually been used in competitive benchmarking in order to evaluate efficiency of individual economic entities (DMUs) in relation to their competitors. However, another important perspective of using DEA in corporate governance has begun to crystallize recently. In this area, DEA has start to be presented as a tool of internal benchmarking where efficiency is assessed for sub-units within the DMU in question. In this context, several authors have taken advantage of this new application of DEA and applied DEA to the PA in different industries of economy. For example, Osman et al. (2011) proposed the DEA approach for the PA of nurses. The model was validated with 32 nurses working at an Intensive Care Unit (ICU) at one of the most recognized hospitals in Lebanon. Shirouyehzad et al. (2012) used DEA to evaluate employees' efficiency in a pipe company in Iran by using 55 employees as the sample. Tao (2012) combined the workforce scorecard and DEA to evaluate multi-department employee performance in a Chinese motor company. Zbranek (2013) applied DEA for the performance evaluation of 60 employees in a bakery company. Dugelová and Strenitzerová (2015) used DEA for performance evaluation of 12 employees in the international IT company in the Slovak Republic. Mahmudah and Lola (2018) estimated the efficiency of 102 employees in a Malaysian shipping company under profit sharing system, using a robust DEA approach. And finally, Najar et al. (2018) proposed the DEA matrix (DEAM) approach for the performance assessment of 30 nurses from the cardiology department of a hospital in Iran. Although there are several DEA applications to evaluate aggregate call centres performance (e.g. So, 2007; Abuelwafa, 2014), as far as we know, there is only one study (Abuelwafa, 2014) that applies DEA for the PA of call centre agents. Abuelwafa (2014) applied DEA to real three-month's aggregated performance data for 30 agents who work in different queues in the 
same account of the call centre in the Middle East North Africa region. The data the author used consisted of one input, viz. queue service capacity target per hour, and three outputs, viz. (i) productivity (service capacity), (ii) quality, and (iii) punctuality (average of adherence and attendance). This study can be considered the first one, which has shown that the use of DEA in PA agents has its irrefutable advantages. However, to date there is no comprehensive methodology on how to apply DEA properly to assess call centre agents' performance.

As the use of DEA in PA is a relatively new aspect of its application and could be an effective and useful management tool for evaluation of call agents' performance as well, the main aim of this paper is to propose a DEA approach for the performance evaluation of call centre agents based on their relative efficiency. In the paper, the proposed DEA approach is validated with 55 live agents working at a call centre in one of the largest telecommunications operators in the Slovak Republic. It is anticipated that the methodology suggested herein may be recommended to the PA in similar sectors.

The paper organization is as follows. Section 1 gives background on call centre agents' performance assessment. In Section 2, a new proposed DEA methodology in the PA of call centre agents is clarified. Section 3 presents the results of the empirical analysis in which the proposed DEA methodology is applied to assess the performance of the inbound call centre agents working for one of the largest telecommunications operators in the Slovak Republic. The final section summarizes and concludes the paper.

\section{Background}

Acall centre plays the key role in determining the satisfaction levels of the company's customers. It can be said that customers' satisfaction with the call centre services determines the customers' satisfaction with the company as a whole. Call centres can act as an in-house call centre established and run by the company in its headquarters, or an outsourced call centre run by an external company. In addition to this classification, call centre types are usually classified according to the type of calls they engage in. Call centres can be classified as (i) the inbound call centres where the customers call directly and require certain services, or (ii) the outbound call centres where the call centre agents make a direct contact with the customers for the purpose of various marketing and business activities. For more details on development, characteristics and importance of call centres to the companies, refer to Anton (2000), Houlihan (2002), or Fielding (2003).

So as to guarantee high quality services and customer satisfaction, the call centre agents are guided and monitored by several KPIs. Anton (1997) suggested a group of $23 \mathrm{KPI}$ applicable in the call centres and classified them as operationrelated, income-related, cost-related and servicequality-related indicators. Apart from that, the Customer Operation Performance Centre (COPC), an international call centre-related certificate authority, uses a total of $32 \mathrm{KPIs}$ for the four domains: leadership/planning, process, people, and performance. The companies manage their call centres in like manner, i.e. with various KPIs, to improve the quality of service and to maximize customer satisfaction. Although many traditional quantitative and judgmental methods in the PA have been proposed (for more details see, e.g., Jafari et al., 2009; Armentrout, 1986; Arvey \& Murphy, 1998), and call centre performance is a multi-dimensional problem, it is necessary to use more capable tools to help define overall performance on a single scale. One of the most commonly used techniques for performance measurement in call centres is benchmarking. Benchmarking enables quantification of the call centre performance, comparison of the call centre performance with the other call centres in industry, identification of the negative performance gaps, and definition of action needed in order to eliminate these gaps. One of the companies that provide information on benchmarks, scorecards and KPIs to the information technology and contact centre professionals worldwide is, for instance, MetricNet, LLC Company. MetricNet's benchmarking database is global and collects more than 3,700 benchmarks. Through them, MetricNet has identified nearly 80 industry best practices and $30 \mathrm{KPIs}$ that companies around the world are using to achieve world-class performance.

However, this way of KPIs industry best practices comparison carries a risk of several limitations: (i) Performance comparison is usually conducted in the whole call centre (regardless the performance of the individual agents); (ii) Own gathering of the benchmarking values for $\mathrm{KPIs}$ is extremely time-consuming 
and often even impossible, as the companies neither have to, nor want to provide internal information to the external subjects; (iii) Gathering of the benchmarking values for KPIs by the external companies (such as MetricNet) is often expensive as there are usually very strict financial conditions; (iv) Disregard of the specific conditions and character of the call centre, as mutual comparability in the industry can be insufficient; (v) Missing composite indicator that would speak of the call centre's overall achieved performance (simple comparison of the multiplex KPIs groups with the benchmarks does not necessarily bring clear results); (vi) Regard only for the output performance criteria, with no direct link to the input characteristics that may considerably affect the call centre agents' performance.

Apparently, from the foregoing it follows that the new methods for improvement of the call centre agents' evaluation are necessary. One option for elimination of the above-mentioned shortcomings of the traditional PA methods is the application of DEA. The main aim of this paper is to propose such DEA approach that would, in addition to the output performance indicators, also take the input characteristics of the individual call center agents into account, and thus provide a composite indicator of their overall performance.

\section{Methodology: the Proposed DEA Approach}

DEA is based on Farrell's methodology (see Farrell, 1957), which rests on a nonparametric construction of the production possibility frontier (PPF) through linear programming. The main idea of DEA is to determine the efficiency of the DMUs, based on their distance from the constructed PPF. In terms of methodology, the process of DEA application for the purpose of measuring efficiency in any DMUs group consists of the following crucial footsteps: (i) definition and selection of the DMUs, (ii) definition and selection of appropriate inputs and outputs for the analysis, (iii) selection and formulation of the most appropriate DEA model, and (iv) DEA results presentation.

\subsection{Definition and Selection of the DMUs}

In DEA, homogeneous DMUs with an ultimate goal of improving their performance have to be used. A homogeneous set of the DMUs can be obtained by considering the following two main criteria (Ozbek et al., 2009): (i) the DMUs should be performing the same tasks with similar objectives, and (ii) the input-output variables characterizing the process of the DMUs in the data set should be identical, except for the differences in their magnitude or values. It follows that to attain a set of homogeneous DMUs for DEA, it is essential that the agents to be compared perform similar activities.

\subsection{Identification of the Inputs and Outputs of Call Centre Agents' Activity}

The basis for the application of DEA in the PA of call centre agents is that each agent can be seen as a DMU, which transforms a set of inputs into a set of outputs. On the grounds of the relationship between inputs and outputs, DEA could identify inefficient agents and suggest options to eliminate their inefficiencies. The group of inputs may include: (i) the socio-demographic indicators, which define physical and mental abilities of an agent, such as age, education, qualification, professional experience, talents, etc, and/or (ii) the economic indicators like wage, training hours, working hours, overtime hours, agent schedule adherence, etc. The group of outputs characteristic for the agent's work activity can be described with either (i) handle time indicators, e.g. inbound/outbound contact handle time, talk time, after call work time, etc, (ii) quality indicators, e.g. customer satisfaction, net first contact resolution rate, call quality, quick-answer calls proportion, successful calls proportion, etc and/or (iii) the economic indicators like the number of newlyacquired customers, the number of newlyconcluded contracts, value of newly-concluded contracts, etc.

In addition to these input and output variables, which are directly related to the agents' activity, in practice there could be other factors that are beyond the agents' own control but have a significant impact on their activity. In the DEA terminology, these factors are often referred to as environmental variables, which express the environmental impact on the DMU and characterize the environment in which the DMU operates. An example of the environmental variables in a call centre can be (i) work environment indicators, e.g. 
physical environment conditions (workplace noise levels, lighting, etc), or social working conditions (number of people in the office, the office size, etc), or (ii) external factors such as the number of inbound contacts, etc. DEA provides several approaches that enable taking the impact of the environmental variables in efficiency measurement into account.

In this paper, the proposed DEA approach is implemented in one of the largest telecommunications operators in the Slovak Republic. As an integrated telecommunications operator, it provides multiple services through its mobile and fixed networks. Live agents help clients with their requirements and provide information about the company's products and services. To assess the performance of the call centre and the individual live agents, the company regularly sets organization-wide goals and uses metrics to follows up their achievement through particular objectives. On a monthly basis, the company monitors a set of KPIs that are used to judge the live agents' performance. Out of a relatively large number of monitored KPIs, a total of 10 most important indicators, based on an expert assessment of the company managers, were selected. These were then classified into a set of inputs and outputs according to their character. Tab. 1 presents input and output variables with their notations and definitions. The data characterizing the activities of 55 live agents in 2017, were provided to the authors by the company and are available on request. Tab. 2 presents the summary statistics of the considered variables.

The W, AATH, WT, and AO variables represent the factors determining the results of the agent's activity. Since their minimization should be considered in terms of improving

\section{Tab. 1: All considered variables}

\begin{tabular}{l|c|c|l}
\multicolumn{1}{c|}{ Variable } & $\begin{array}{c}\text { Measurement } \\
\text { unit }\end{array}$ & Notation & \multicolumn{2}{c}{ Definition } \\
\hline Wage & EUR & W & The average monthly wage of the agent \\
\hline $\begin{array}{l}\text { Annual agent } \\
\text { training hours }\end{array}$ & Hours & AATH & $\begin{array}{l}\text { The average number of training hours (including } \\
\text { classroom, self-study, etc) that the agent receives } \\
\text { on an annual basis }\end{array}$ \\
\hline \begin{tabular}{l|c|l} 
Working time \\
Agent occupancy
\end{tabular} & Hours & WT & $\begin{array}{l}\text { The average monthly number of hours at work } \\
\text { (excluding break and lunch time) }\end{array}$ \\
\hline $\begin{array}{l}\text { Inbound contacts } \\
\text { Number }\end{array}$ & IC & $\begin{array}{l}\text { The percentage of time that the agent spends } \\
\text { on handling incoming contacts, divided by the total } \\
\text { number of hours at work (excluding break and lunch } \\
\text { time) }\end{array}$ \\
\hline $\begin{array}{l}\text { Quick-answer } \\
\text { calls proportion }\end{array}$ & $\%$ & QACP & $\begin{array}{l}\text { The perage monthly incoming call volume } \\
\text { within 30 seconds }\end{array}$ \\
\hline $\begin{array}{l}\text { Customer } \\
\text { satisfaction }\end{array}$ & $\%$ & CS & $\begin{array}{l}\text { The percentage of customers who are either satisfied } \\
\text { or very satisfied with the agent's work }\end{array}$ \\
\hline $\begin{array}{l}\text { Net first contact } \\
\text { resolution }\end{array}$ & \% & NFCR & $\begin{array}{l}\text { The percentage of calls that are resolved on the first } \\
\text { interaction with the customer divided by all calls that } \\
\text { are potentially resolvable on first contact }\end{array}$ \\
\hline $\begin{array}{l}\text { Call quality } \\
\text { Inbound contact } \\
\text { handle time }\end{array}$ & Seconds & ICHT & $\begin{array}{l}\text { The average time that the agent spends on the contact, } \\
\text { including talk time, wrap time, and after call work time } \\
\text { (on a scale of 0\% [the worst] to 100\% [the best]) }\end{array}$ \\
\hline
\end{tabular}


efficiency, they are included in the group of inputs. The input variable IC expressing the average monthly incoming call volume represents environmental variable, which is beyond the agents' control, but which has a significant impact on agents' activity. On the other hand, the QACP, CS, NFCP, CQ and ICHT variables cover the results of the agents' activity represented by the quality of the calls made. Since their maximization should be considered in terms of improving efficiency (except for the ICHT variable), they are included in the group of outputs. The ICHT variable has a special position in the output group. This variable has the character of undesirable output that needs to be reduced in order to improve efficiency.

When selecting an appropriate combination of inputs and outputs for DEA, it is necessary to consider the following main aspects: (i) suitability of variables with respect to the economic definition of efficiency; (ii) meeting the condition of the maximum number of inputs and outputs in relation to the number of DMUs, and (iii) uniqueness of information contained in inputs and outputs underlined by a strong relationship between inputs and outputs, i.e. the outputs should be generated directly by the respective inputs. In accordance with the condition stated by Cooper et al. (2007, p. 116), i.e. that the number of DMUs needs to be at least three times greater than the number of inputs and outputs, in the following efficiency evaluation the agents allow for maximum of 18 input and output variables. Since, as Tab. 1 shows, we consider 10 variables, this condition is met sufficiently.

The WT and AO inputs characterize the timeconsuming aspect of the agents' activity. From a theoretical point of view, it can be assumed that working time increase will cause the agent to handle more calls. As a result, the agent should gain more experience, which in turn will help them improve the quality of their work. This assumption is also confirmed by the examined correlations (see Tab. 3) where the WT variable manifests positive linear correlations with the QACP, CS and NFCP outputs, and negative linear correlations with the ICHT output. On the other hand, an increase in the $\mathrm{AO}$ variable does not necessarily lead to an increase in the outputs considered. This is also confirmed by the correlation assessment (Tab. 3), where the $A O$ variable records negative linear correlations with the NFCP and CQ outputs. If two agents use the same quantity of inputs to produce the same quantity of outputs and only the $\mathrm{AO}$ of the first agent is lower than the $A O$ of the second agent, the first one cannot be said to be more efficient as it is clear that a smaller part of total working time was devoted to the main work

\section{Tab. 2: Summary statistics of considered variables}

\begin{tabular}{l|c|c|c|c|c} 
& Average & Median & Max $^{\mathbf{a}}$ & Min $^{\text {a }}$ & Stdev \\
\hline \multicolumn{7}{|c|}{ INPUTS } \\
\hline W & 691.2 & 706.0 & $888.0(A 37, A 38)$ & $451.0(A 41)$ & 132.3 \\
\hline AATH & 17.3 & 11.0 & $122.0(A 11)$ & $\begin{array}{c}0(A 19, A 22, A 23, A 33, \\
\text { A34, A35, A38, A44, A55) }\end{array}$ & 21.1 \\
\hline WT & 123.9 & 121.0 & $165.0(A 31)$ & $77.0(A 16, A 51)$ & 27.0 \\
\hline AO & 48.2 & 48.3 & $67.0(A 15)$ & $31.5(A 36)$ & 8.1 \\
\hline IC & 427.0 & 347.0 & $1533.0(A 51)$ & $54.0(A 13)$ & 319.7 \\
\hline QACP & 43.2 & 44.1 & $78.1(A 40)$ & $16.2(A 41)$ & 14.6 \\
\hline CS & 36.5 & 39.3 & $64.6(A 40)$ & $12.1(A 8)$ & 12.9 \\
\hline NFCP & 24.4 & 23.4 & $51.9(A 11)$ & $10.4(A 12)$ & 9.4 \\
\hline CQ & 39.0 & 37.2 & $81.6(A 11)$ & $11.7(A 34)$ & 16.1 \\
\hline ICHT & 145.2 & 167.1 & $277.8(A 51)$ & $12.4(A 40)$ & 63.6 \\
\hline
\end{tabular}


activity. The $\mathrm{AO}$ variable aggregates two factors: the working time factor and the external factor of the inbound calls volume. In order to take both factors into account and avoid duplication, from the WT, AO and IC variables we select the WT variable which characterizes the working time factor, and the IC variable which expresses the external factor of the incoming calls volume.

As Tab. 3 shows, in the case of the AATH variable, the assumption of dependency of outputs on this input is disrupted for three outputs (QACP, CS and CHT). The broad range of development and training activities that the company provides to its employees in order to diversify and expand knowledge and skills of the agents does not produce a positive result for all outputs in terms of improving the quality of the agents' activity. This should be a signal to the company to review the ways and means of delivering training activities so that they are, as much as possible, involved in improving the quality of services provided. However, since the assumption of direct dependence of outputs on this input is not met, the AATH variable is not further considered in our analysis.

\section{Tab. 3: Correlations between considered variables}

\begin{tabular}{|c|c|c|c|c|c|c|c|c|c|c|c|}
\hline & & \multicolumn{5}{|c|}{ INPUTS } & \multicolumn{5}{|c|}{ OUTPUTS } \\
\hline & & w & AATH & WT & AO & IC & QACP & CS & NFCP & $C Q$ & ICHT \\
\hline \multirow[t]{5}{*}{ INPUTS } & W & 1 & & & & & & & & & \\
\hline & AATH & -0.2331 & 1 & & & & & & & & \\
\hline & WT & -0.2034 & -0.2921 & 1 & & & & & & & \\
\hline & AO & -0.2031 & -0.1590 & -0.0369 & 1 & & & & & & \\
\hline & IC & -0.0168 & 0.2809 & -0.0200 & -0.3174 & 1 & & & & & \\
\hline \multirow[t]{5}{*}{ OUTPUTS } & QACP & 0.1980 & -0.2177 & 0.4944 & 0.6771 & -0.2237 & 1 & & & & \\
\hline & CS & 0.3562 & -0.1643 & 0.0096 & 0.8053 & -0.2704 & 0.8669 & 1 & & & \\
\hline & NFCP & 0.3634 & 0.6171 & 0.1604 & -0.1112 & 0.1821 & 0.3962 & 0.3131 & 1 & & \\
\hline & $C Q$ & 0.5573 & 0.5952 & -0.0799 & -0.1781 & 0.1861 & 0.2719 & 0.3063 & 0.9554 & 1 & \\
\hline & ICHT & -0.0447 & 0.1919 & -0.8546 & -0.3072 & 0.0988 & -0.8581 & -0.4962 & -0.4429 & -0.2360 & 1 \\
\hline
\end{tabular}

Based on all the aforementioned arguments, the reduced group of inputs (W, WT and IC) is considered further. This selection ensures that the group of the outputs is directly generated by the group of the selected inputs.

Moreover, from the managerial point of view, it is a well-known fact that the individual KPIs do not have an equal importance in terms of the agents' activity assessment. It is generally believed that KPIs characterizing customer service, customer satisfaction and level of service are considered to be most important (see, e.g., Robinson \& Morley, 2006). In the analysed call centre, it holds that in the group of inputs the wage (W) is perceived as approximately two-times more significant than working time (WT). In the group of outputs, the evaluation of calls by the customers (CS) is considered most important, the proportion of calls that were resolved on the first interaction with the customer (NFCR) and evaluation of the calls by the internal evaluator (CQ) are of approximately equal importance, the proportion of quickly answered calls (QACP) and the handle time (ICHT) are also almost equally important. The CS indicator has about twice as high importance as the NFCR and $\mathrm{CQ}$ indicators, and about three-times higher importance than QACP and ICHT indicators.

\subsection{The DEA Model Formulation}

After the selection of the inputs and outputs, it is necessary to choose and formulate the most convenient DEA model in relation to the actual problem. In identifying the most appropriate DEA model, the following DEA classification criteria may be used. The first one represents the perspective of the inefficiency form that can 
be identified with DEA. The second criterion is return to scale assumption, and the third one is the choice of DEA model orientation, or the choice of efficiency aspect that is to be quantified with DEA. The selection of DEA model should especially result from the formulated analysis objective and the nature of the inputs and outputs considered.

In terms of the first criterion, it is possible to use either (i) radial models (e.g. the CCR model by Charnes et al., 1978, or the BCC model by Banker et al., 1984), (ii) non-radial models (e. g. the additive model by Charnes et al., 1985; or the SBM model by Tone, 2001), or (iii) hybrid models. Radial models consider the radial or proportional nature of the variables under consideration and quantify weak Farrell efficiency. Non-radial models consider the non-radial or non-proportional nature of the variables considered and quantify strong Pareto-Koopmans efficiency. Hybrid models are applicable in the cases when in the set of inputs (outputs) there are the indicators with both radial and non-radial character. In our analysis, due to the prevailing non-radial nature of the variables considered (inputs/outputs can be changed independently of the other inputs/ outputs), non-radial models represent a more appropriate and comprehensive alternative to radial or hybrid models.

In terms of the second criterion, it is necessary to make a choice of the assumed returns to scale. In general, the constant returns to scale (CRS) or the variable returns to scale (VRS) can be assumed. Overall inefficiency that an agent might show could be caused by an inefficient operation of an agent himself, i.e. pure inefficiency, or by the disadvantageous conditions under which an agent is operating, i.e. scale inefficiency. While the pure technical efficiency reveals an ability of an agent to achieve the PPF in the short term, the scale efficiency indicates an ability of an agent to adjust the scale of his operations in the long term. It follows from the foregoing that if only pure efficiency needs to be evaluated, the VRS assumption should be selected, and if overall efficiency needs to be evaluated, the CRS assumption should be preferred. Here it should be noted that the assumption of CRS is appropriate only when all agents work at their optimal level. In reality, however, some factors like workload, stress and pressure can prevent the agents from working at their optimal level. As for elimination of the influence of scale inefficiency for the purposes of the agents' efficiency measurement, it is more appropriate to use the VRS assumption. The CRS assumption can be used if the goal is to measure long-term efficiency (when the shortterm efficiency variances, are not permitted as a result of the factors mentioned above), while the VRS assumption is more appropriate for the short-term efficiency measurements (when the potential negative influence of the previously mentioned factors on the efficiency achieved is taken into account). In our analysis, we consider both the CRS and VRS assumptions, as our effort is to evaluate and compare the efficiency of call centre agents both in the long and short terms.

The third criterion requires the choice of model orientation. We can use either (i) the input-oriented model when, in terms of efficiency increase, it is more appropriate to consider the potential decrease of the used input level at the given output level, (ii) the output-oriented model when, in terms of efficiency increase, it is more appropriate to consider the potential increase of the produced output level at the given input level, or (iii) the non-oriented model which allows simultaneous decrease of the inputs used and increase of the outputs achieved. It is obvious that while the oriented models reveal only the input or output efficiency, the non-oriented models aggregate both efficiency aspects and quantify overall efficiency. Since the goal in our analysis is to assess the overall performance of the call centre agents and identify all aspects of their efficiency, the non-oriented model is used in the analysis. As will be shown later, also the non-oriented model allows us to quantify the input efficiency (the ability of the agents to use optimal quantities of inputs with respect to the outputs achieved), and the output efficiency (the ability of the agents to achieve the optimum output levels with respect to the inputs used) separately. While the input efficiency measurement will enable identification of those agents who waste some inputs (agents with excess inputs), the output efficiency measurement will enable identification of those agents for whom there is room for improvement in the outputs achieved (agents with shortfalls in outputs).

Last but not least, in selecting a DEA model, it is necessary to take the specific characteristics of the considered variables 
into account. Although the input IC variable affects the level of outputs achieved, the agents themselves do not have a direct impact on its level. This variable represents an external environmental variable that can be included in the DEA efficiency assessment in the form of an uncontrollable input variable. Moreover, it is necessary to take under advisement that the values of some inputs/outputs cannot be changed at discretion. Given the nature of the inputs considered (W and WT), we assume that their level can be changed without any limitation. The wage reduction below the minimum wage level as stipulated in the national legislation is possible, for instance, by changing the fulltime employment contract of an agent to an "agreement on work performance" (service agreement), where the lower limit for wage or working time is not defined in the Slovak legislation. On the side of the outputs, however, there are some limitations of their possible changes. The QACP, CS, NFCP and CQ variables are expressed as a percentage, so the upper bound for the projected values of these variables is $100 \%$. As stated before, the ICHT variable has a special position in the output group due to its undesirable output character. Moreover, even this variable cannot be reduced without limitation. There is certain minimum duration for each call. For the incoming calls, the agents have to introduce themselves and the company they represent, listen to the caller's request, and then provide a relevant answer. To take these variable constraints into account, the DEA models with bounded variables are commonly applied. Finally, it is necessary to consider the different importance of the individual inputs and outputs. For this purpose, the weighted forms of the DEA models could be used.

All aforementioned requirements are satisfied by using the non-oriented weighted
Slack-Based Measure model by Tone (2001) with non-controllable input variables, and bounded and undesirable output variables, hereinafter referred to as the WSBM model with no explicit emphasis on the fact that it is adjusted to consider specific variables. The general mathematical formulation of the WSBM model under the CRS assumption (WSBM-C model) can be constructed in the following exposition.

Let us consider the case of $n$ DMUs. Let us assume that each DMU $i, i \in(1, \ldots, n)$, transforms $m$ inputs represented by the vector $\mathbf{x}_{i}=\left(x_{1 i}, \ldots, x_{m i}\right)^{\prime} \in R_{+}^{m}$ into $s$ outputs represented by the vector $\mathbf{y}_{i}=\left(y_{1 i}, \ldots, y_{s i}\right)^{\prime} \in R_{+}^{s}$. The group of $m$ inputs of DMU $i$ consists of a subset of $m_{1}$ controllable inputs represented by the vector $\mathbf{x}_{i}^{\mathrm{C}}=\left(x_{1 i}^{\mathrm{C}}, \ldots, x_{m_{1}}^{\mathrm{C}}\right)^{\prime} \in R_{+}^{m_{1}}$ and a subset of $m_{2}$ noncontrollable inputs represented by the vector $\mathbf{x}_{i}^{\mathrm{NC}}=\left(x_{1 i}^{\mathrm{NC}}, \ldots, X_{m_{2}}^{\mathrm{NC}}\right)^{\prime} \in R_{+}^{m_{2}}$, with $m_{1}+m_{2}=m$. The group of $s$ outputs of DMU $i$ consists of two subsets: a subset of $s_{1}$ desirable outputs represented by the vector $\mathbf{y}_{\mathrm{i}}^{\mathrm{D}}=\left(y_{1 i}^{\mathrm{D}}, \ldots y_{\mathrm{s}_{i}}^{\mathrm{D}}\right)^{\prime} \in R_{+}^{s_{1}}$ and a subset of $S_{2}$ undesirable outputs represented by the vector $\mathbf{y}_{i}^{\mathrm{UD}}=\left(y_{1 i}^{\mathrm{UD}}, \ldots, y_{s_{2}}^{\mathrm{UD}}\right)^{\prime} \in R_{+}^{s_{2}}$. Obviously, $s_{1}+s_{2}=S$. In order to take the differences in importance of the individual indicators into account, we shall establish normalized weights of relative importance for controllable inputs $\mathbf{w}^{\mathrm{C}}=\left(w_{1}^{\mathrm{C}}, \ldots, w_{m_{1}}^{\mathrm{C}}\right)^{\prime}, \sum_{j=1}^{m_{1}} w_{j}^{\mathrm{C}}=m_{1}$ and normalized weights of relative importance for desirable outputs $\mathbf{w}^{\mathrm{D}}=\left(w_{1}^{\mathrm{D}}, \ldots, w_{s 1}^{\mathrm{D}}\right)^{\prime}$ and undesirable outputs $\mathbf{w}^{\mathrm{UD}}\left(w_{1}^{\mathrm{UD}}, \ldots, w_{s_{2}}^{\mathrm{UD}}\right)^{\prime}$, with $\sum_{r=1}^{s_{1}} w_{r}^{\mathrm{D}}+\sum_{r=1}^{s_{2}} w_{r}^{\mathrm{UD}}=s_{1}+s_{2}$. ForthegivenDMU $i$, $i \in(1, \ldots, n)$, let the vectors $\mathbf{u}_{\mathrm{i}}^{\mathrm{D}}=\left(u_{1 i}^{\mathrm{D}}, \ldots, y_{\mathrm{s}_{1}}^{\mathrm{D}}\right)^{\prime} \in R_{+}^{s_{1}}$ and $\mathbf{l}_{i}^{\mathrm{UD}}=\left(l_{1 i}^{\mathrm{UD}}, \ldots, l_{s_{2}}^{\mathrm{UD}}\right)^{\prime} \in R_{+}^{s_{2}}$ represent the upper and the lower bounds of desirable and undesirable outputs, respectively. Based on this distinction, the optimization task of the WSBM-C model as specified before for each DMU $o, o \in(1, \ldots, n)$ is formulated in (1):

$$
\begin{aligned}
& 1-\frac{1}{m_{1}} \sum_{j=1}^{m_{1}} w_{j}^{\mathrm{C}} \frac{S_{j o}^{\mathrm{C}}}{x_{j o}^{\mathrm{C}}} \quad \text { subject to }
\end{aligned}
$$

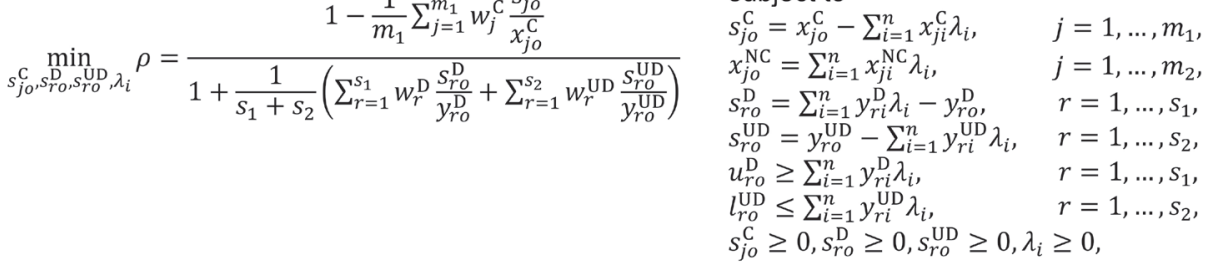

where $\lambda_{i}$ is an intensity variable connected with DMU $i, \mathbf{s}_{o}^{\mathrm{C}}=\left(s_{10}^{\mathrm{C}}, \ldots, s_{\mathrm{s}_{0}}^{\mathrm{C}}\right)^{\prime}$ is a vector of potential slacks (excesses) of the controllable inputs, $\mathbf{s}_{o}^{\mathrm{D}}=\left(s_{10}^{\mathrm{D}}, \ldots, S_{\mathrm{s}_{1}}^{\mathrm{D}}\right)^{\prime}$ is a vector of potential 
slacks (shortfalls) of the desirable outputs, $\mathbf{s}_{o}^{\mathrm{UD}}=\left(s_{1 o}^{\mathrm{UD}}, \ldots, s_{\mathrm{S}_{0}}^{\mathrm{UD}}\right)^{\prime}$ is a vector of potential slacks (excesses) of the undesirable outputs, and $\rho$ is a WSBM efficiency score taking the values in the interval $(0,1]$. The optimization task of the WSBM model under VRS assumption (WSBM-V model) takes the form of (1) with an additional constraining condition $\sum_{i=1}^{n} \lambda_{i}=1$.

Let an optimal solution for the program (1) be $\left(\rho^{*}, \mathbf{s}_{o}^{\mathrm{C} *}, \mathbf{s}_{o}^{\mathrm{D} *}, \mathbf{s}_{o}^{\mathrm{UD} *}, \lambda^{*}\right)$. It is obvious that the DMU $o\left(\mathbf{x}_{o}^{\mathrm{C}}, \mathbf{x}_{o}^{\mathrm{NC}}, \mathbf{y}_{o}^{\mathrm{D}}, \mathbf{y}_{o}^{\mathrm{UD}}\right)$ may be called WSBM-efficient if and only if $\rho^{*}=1$, i.e. $\mathbf{s}_{o}^{\mathrm{C} *}=\mathbf{0}, \mathbf{s}_{o}^{\mathrm{D} *}=\mathbf{0}$ and $\mathbf{s}_{o}^{\mathrm{UD} *}=\mathbf{0}$. A DMU that does not meet this requirement may be termed as WSBM-inefficient.

For a WSBM-inefficient DMU, i.e. a DMU with $\rho^{*}<1$, let a vector of the projected controllable inputs be denoted by $\hat{\mathbf{x}}_{o}^{C}=\left(\hat{x}_{10}^{\mathrm{C}}, \ldots, \hat{x}_{m_{10}}^{\mathrm{C}}\right)^{\prime}$, a vector of the projected desirable outputs be denoted by $\hat{\mathbf{y}}_{o}^{D}=\left(\hat{y}_{10}^{\mathrm{D}}, \ldots, \hat{y}_{s_{10}}^{\mathrm{D}}\right)^{\prime}$, and a vector of projected undesirable outputs be $\hat{\mathbf{y}}_{o}^{\mathrm{UD}}=\left(\hat{y}_{1 o}^{\mathrm{UD}}, \ldots, \hat{y}_{S_{20}}^{\mathrm{UD}}\right)^{\prime}$. The WSBM projection is given by (2):

$$
\begin{aligned}
& \hat{\mathbf{x}}_{o}^{\mathrm{C}}=\mathbf{x}_{o}^{\mathrm{C}}-\mathbf{s}_{o}^{\mathrm{C} *} \\
& \hat{\mathbf{y}}_{o}^{\mathrm{D}}=\mathbf{y}_{o}^{\mathrm{D}}+\mathbf{s}_{o}^{\mathrm{D} *} \\
& \hat{\mathbf{y}}_{o}^{\mathrm{UD}}=\mathbf{y}_{o}^{\mathrm{UD}}-\mathbf{s}_{o}^{\mathrm{UD} *}
\end{aligned}
$$

Using the optimal solution $\left(\rho^{*}, \mathbf{s}_{o}^{\mathrm{C} *}, \mathbf{s}_{o}^{\mathrm{D} *}, \mathbf{s}_{o}^{\mathrm{UD} *}\right.$, $\lambda^{*}$ ), the WSBM efficiency score $\rho^{*}$ can be factorized into two factors, the input efficiency score $\rho_{I}{ }^{*}$ and the output efficiency score $\rho_{0}{ }^{*}$, using the following decomposition:

where

$$
\rho_{\mathrm{I}}^{*}=1-\frac{1}{m_{1}} \sum_{j=1}^{m_{1}} w_{j}^{\mathrm{C}} \frac{s_{j o}^{\mathrm{C} *}}{x_{j o}^{\mathrm{C}}} \quad \text { and } \quad \rho_{0}^{*}=1 /\left[1+\frac{1}{s_{1}+s_{2}}\left(\sum_{r=1}^{s_{1}} w_{r}^{\mathrm{D}} \frac{s_{r o}^{\mathrm{D} *}}{y_{r o}^{\mathrm{D}}}+\sum_{r=1}^{s_{2}} w_{r}^{\mathrm{UD}} \frac{s_{r o}^{\mathrm{UD} *}}{y_{r o}^{\mathrm{UD}}}\right)\right]
$$

This expression indicates that WSBM inefficiency, i.e. $\rho^{*}<1$, is a result of the existence of input inefficiency $\rho_{\mathrm{I}}^{*}<1$ and/or output inefficiency $\rho_{0}^{*}<1$.

The general mathematical formulation of the WSBM model (1) can be naturally adjusted to specific cases. In terms of measuring the efficiency of the 55 call centre agents, the vector of inputs for the given agent $i, i \in(1, \ldots, 55)$, consists of two controllable inputs included in $\mathbf{x}_{i}^{\mathrm{C}}=\left(x_{1 i}^{\mathrm{C}}, x_{2 i}^{\mathrm{C}}\right)^{\prime}$, where $x_{1 i}^{\mathrm{C}}$ denotes the variable $\mathrm{W}$ and $x_{2 i}^{\mathrm{C}}$ stands for the variable WT, and one uncontrollable input $x_{1 i}^{\mathrm{NC}}$ representing the variable IC. The vector of outputs consists of four desirable outputs QACP, CS, NFCP and CQ denoted by $\mathbf{y}_{i}^{\mathrm{D}}=\left(y_{1 i}^{\mathrm{D}}, y_{4 i}^{\mathrm{D}}\right)^{\prime}$ and one undesirable output ICHT denoted by $y_{1 i}^{\mathrm{UD}}$. Moreover, since the variables QACP, CS, NFCP and $C Q$ are expressed as a percentage, the upper bound for the projected values of these variables was naturally set at $100 \%$, i.e. $u_{r o}^{\mathrm{D}}=100 \%$. In the case of undesirable output ICHT, the model (1) considers its minimization. However, as mentioned earlier, it cannot be minimized without any restrictions. It is unimaginable for the agent to be able to reduce incoming contact handle time to 0 seconds. Therefore, the lower bound for this output was set at 10 seconds, i.e. $l_{1 o}^{\mathrm{UD}}=10$. This threshold is the lowest possible duration of the shortest call. In conclusion, the above mentioned assumptions regarding the relative importance of the individual KPIs correspond with the weights of the controllable inputs $\mathbf{w}^{\mathrm{C}}=(4 / 3,2 / 3)^{\prime}$ and the weights of relative importance for the desirable outputs $\mathbf{w}^{\mathrm{D}}=(5 / 8,15 / 8,15 / 16,15 / 16)^{\prime}$ and an undesirable output $w^{\mathrm{UD}}=5 / 8$.

\subsection{The DEA Results Presentation}

In order to analyse the results taken from the WSBM-C and WSBM-V models, a DEA Matrix (DEAM) based on the approach presented by Osman et al. (2011) or Najar et al. (2018) is used. Using the decomposition (3), the WSBM-C efficiency score is disentangled into the input efficiency score and the output efficiency score. While input inefficiency is observed in those agents who waste some inputs (agents with nonzero excesses in some inputs), output inefficiency is observed in those agents where 
some scope for improving the quality of the outputs achieved is possible (agents with nonzero shortfalls in some desirable outputs, or nonzero excesses in undesirable output). By comparing the resulting input efficiency score and output efficiency score, it is possible to evaluate the strengths and weaknesses of the individual agents in more detail, as well as to identify the groups of agents to which the same form of personnel policy can be applied. To this end, a certain threshold value can be set for both efficiency scores to separate the low-efficient agents (with a score less than the threshold value) from the high-efficient agents (with a score higher than the threshold value). Then, according to their joint efficiency evaluation, the agents are grouped into four groups similar to the ones observed in the BCG matrix (Hedley, 1976): Stars; Cash Cows; Question Marks and Poor Dogs. Stars group is formed of those agents that achieve relatively high input efficiency and relatively high output efficiency. Cash Cows group is formed of those agents that have some unused inputs, but the results of their activity are relatively satisfying. Question Marks group includes those agents that achieve relatively high input efficiency but relatively low output efficiency. The agents that achieve relatively low input inefficiency, as well as relatively low output inefficiency, are included in the last Poor Dogs group.

Because the WSBM-C model is based on the CRS assumption, it is relatively strict in terms of identifying the efficient agents. Its results can be seen as the overall efficiency assessment in the long term. The CRS assumption presupposes that all agents work at their optimum level. However, this may not be always possible in the short term, due to the influence of the external factors such as workload, stress and pressure. To take the impact of the above-mentioned external factors into account, the WSBM-V model should be applied. By comparing the WSBM-C efficiency score to the WSBM-V efficiency score, managers could acquire further useful information. Also, in this case it is necessary to set a certain threshold value for both the efficiency scores to separate the lowefficient agents from the high-efficient ones. According to their efficiency evaluation based on the WSBM-C and WSBM-V models, the agents could be also divided into four groups: Stars; Cash Cows; Question Marks and Poor Dogs. Stars group consists of the agents who achieve relatively high performance both in the short- and long-term. Poor Dogs group includes the agents with relatively low performance in both the short- and long-term. Cash Cows group is formed of those agents that achieve relatively high performance in the long-term, but their performance in the short-term is relatively low. For these agents, there is a short-term fluctuation in efficiency due to, for instance, the impact of the external factors. And finally, Question Marks group is made up of those agents who achieve relatively high performance in the short-term, but their performance in the long-term is relatively low. The reason that could cause them to be inefficient in the long term could be just the effect of the external factors such as work stress and exhaustion, or temporary (health or social) indisposition.

\section{Results}

Based on the inputs and outputs considered, the WSBM-C and WSBM-V models were solved. The summary comparison of the results of these models is presented in Tab. 4, and the final results of the WSBM-C model for inefficient call centre agents are displayed in Tab. 5.

The results of the WSBM-C model indicate 19 agents achieving full efficiency (the WSBM-C efficiency score equal to 1) and 36 agents achieving inefficiency (the WSBM-C efficiency score less than 1). The average efficiency score of 0.726 means that the average call centre agent shows almost $72.6 \%$ of the best agents' performance. The least efficient agent A30 achieves only $29.9 \%$ efficiency of the agents with the maximum efficiency. The agent A30 can achieve full efficiency by having his/ her wage (W), working time (WT) and incoming call handle time (ICHT) reduced by $43.60 \%$, $52.30 \%$, and $31.39 \%$, respectively, and by increasing customer satisfaction (CS), net first contact proportion (NFCP) and call quality (CQ) by $57.65 \%, 126.59 \%$ and $159.47 \%$, respectively.

From the call centre point of view, the most significant changes need to be made on the output side (for three outputs an average change of over $44 \%$ is needed). For up to 36 agents, the need to reduce the ICHT output is identified. Each inefficient agent has to reduce incoming call handle time by almost $50 \%$ on average. It follows that the main weakness of the agents in the monitored call centre are relatively long-lasting calls. On the other 
Tab. 4: Results of the models used, descriptive statistics

\begin{tabular}{c|c|c|c|c|c|c} 
& Average & Min & Stdev & $\begin{array}{c}\text { Number of } \\
\text { efficient } \\
\text { agents }\end{array}$ & $\begin{array}{c}\text { Number of } \\
\text { inefficient } \\
\text { agents }\end{array}$ & Efficient agents \\
\hline $\begin{array}{c}\text { WSBM-C } \\
\text { model }\end{array}$ & 0.726 & 0.299 & 0.240 & 19 & 36 & $\begin{array}{c}\text { A1, A2, A5, A11, A13, A15, } \\
\text { A16, A17, A19, A20, A24, } \\
\text { A28, A31, A36, A40, A43, } \\
\text { A46, A51, A53 }\end{array}$ \\
\hline $\begin{array}{c}\text { WSBM-V } \\
\text { model }\end{array}$ & 0.794 & 0.312 & 0.227 & 26 & 29 & $\begin{array}{c}\text { A1, A2, A4, A5, A9, A11, A13, } \\
\text { A21, A24, A28, A31, A36, } \\
\text { A40, A41, A43, A46, A48, } \\
\text { A49, A51, A52, A53 }\end{array}$ \\
\hline
\end{tabular}

Source: own

hand, the agents attain a relatively high level of customer satisfaction. Although the need for increase of the $C Q$ variable is identified in up to 20 agents, the rate of changes needed is not too significant. Each inefficient agent has to increase customer satisfaction by only $15.16 \%$ on average. The WSBM-C model also provides a reference set, i.e. the set of agents who are the efficiency benchmarks $\left(\lambda_{i}^{*}>0\right)$ for the inefficient agents. As Tab. 5 shows, the agent A40 is most often referred to as a reference set and is considered a benchmark for up to 23 inefficient agents.

Furthermore, to compare the input and output efficiency of the individual agents, we grouped the agents based on the DEAM framework to determine their performance. Fig. 1 illustrates the input-output-efficiency results with the same threshold value of 0.75 for both efficiency scores. According to the agents' joint efficiency evaluation (Tab. 5), they are divided into four groups based on the relative efficiency scores: (1) Stars (both efficiency scores are higher than 0.75); (2) Cash Cows (the input efficiency score is less than or equal to 0.75 , and the output efficiency score is higher than 0.75 ); (3) Question Marks (the input efficiency score is higher than 0.75 and the output efficiency score is less than or equal to 0.75); and (4) Poor Dogs (both efficiency scores are less than or equal to 0.75 ). Stars group is formed of those agents that achieve relatively high input efficiency, i.e. in terms of quality, they have a relatively low input (W and WT) and relatively high output efficiency; in view of the inputs used, their activity is of relatively high quality. Cash Cows group is formed of those agents that have some unused inputs (relatively high wages and long working time), but the quality of their activity is relatively high. Most such agents included in this group have been in their jobs for a relatively long time, have a level of quality gained from years of experience, or various training sessions, but their wages and working time are relatively high compared to the other younger colleagues. It would be rather risky to focus on reducing costs (wages and working time) in this group of agents. The pressure to reduce the costs of these agents could be counterproductive and demotivating not only for the agents in question, but also for the other agents. Question Marks group includes those agents that are of relatively low cost and relatively poor quality as well. These agents achieve relatively high input efficiency, i.e. with regard to the achieved quality, they use relatively low inputs, but also relatively low output efficiency. So, with regard to the inputs used they achieve relatively low quality. As to this group, it would be advisable that the management focus on supporting the improvement of the agents' performance quality through various training courses, e.g. on job knowledge, communication, etc. Relatively high-cost and low-quality agents are included in the last Poor Dogs group. It is up to the management to decide whether and how these agents should be motivated to improve their performance. As can be seen in Fig. 1, 32 agents $(58.2 \%)$ are in the Star group, 11 agents $(20 \%)$ in the Cash Cows group, 7 agents $(12.7 \%)$ in the Question Mark group, and 5 agents $(9.1 \%)$ in the Poor Dogs group. 


\section{Tab. 5: Results of the WSBM-C model - Part 1}

\begin{tabular}{|c|c|c|c|c|c|c|c|c|c|c|c|}
\hline \multirow{2}{*}{$\begin{array}{l}\text { Agent } \\
\text { ID }\end{array}$} & \multirow[t]{2}{*}{$\rho^{*}$} & \multirow{2}{*}{$\rho_{\mathrm{I}}^{*}$} & \multicolumn{2}{|c|}{$\begin{array}{c}\text { Excesses } \\
\text { (in \%) }\end{array}$} & \multirow{2}{*}{$\rho_{0}^{*}$} & \multicolumn{4}{|c|}{$\begin{array}{l}\text { Shortfalls } \\
\text { (in \%) }\end{array}$} & \multirow{2}{*}{$\begin{array}{c}\begin{array}{c}\text { Excess } \\
\text { (in \%) }\end{array} \\
\mathrm{ICHT} \\
\end{array}$} & \multirow{2}{*}{$\begin{array}{l}\text { Reference } \\
\text { set }\end{array}$} \\
\hline & & & W & WT & & QACP & CS & NFCP & $C Q$ & & \\
\hline A3 & 0.746 & 0.837 & 24.45 & 0 & 0.892 & 6.58 & 0 & 30.66 & 17.20 & 18.91 & $\begin{array}{c}\text { A13, A17, } \\
\text { A46 }\end{array}$ \\
\hline A4 & 0.648 & 0.729 & 40.68 & 0 & 0.889 & 21.57 & 0 & 19.53 & 0 & 49.24 & $\begin{array}{l}\text { A11, A17, } \\
\text { A40, A46 }\end{array}$ \\
\hline A6 & 0.790 & 0.978 & 0 & 6.53 & 0.808 & 26.63 & 36.70 & 0.19 & 0 & 53.15 & $\mathrm{~A} 11, \mathrm{~A} 17, \mathrm{~A} 4 \mathrm{C}$ \\
\hline A7 & 0.687 & 0.881 & 9.32 & 17.13 & 0.780 & 24.28 & 60.48 & 0 & 0 & 20.08 & $\mathrm{~A} 2, \mathrm{~A} 13, \mathrm{~A} 40$ \\
\hline A8 & 0.315 & 0.397 & 59.90 & 61.04 & 0.793 & 4.84 & 46.08 & 2.20 & 0 & 63.07 & $\mathrm{~A} 11, \mathrm{~A} 17$ \\
\hline A9 & 0.718 & 0.973 & 0 & 8.24 & 0.739 & 1.68 & 0 & 57.23 & 89.79 & 60.77 & $\mathrm{~A} 11, \mathrm{~A} 15, \mathrm{~A} 4 \mathrm{C}$ \\
\hline A10 & 0.581 & 0.848 & 4.73 & 36.06 & 0.685 & 0 & 27.39 & 65.34 & 95.46 & 44.05 & $\mathrm{~A} 11, \mathrm{~A} 40$ \\
\hline $\mathrm{A} 12$ & 0.328 & 0.511 & 50.00 & 46.65 & 0.641 & 0 & $\mid 16.22$ & 123.16 & 113.13 & 44.93 & $\mathrm{~A} 11, \mathrm{~A} 17$ \\
\hline A14 & 0.449 & 0.597 & 42.81 & 35.16 & 0.751 & 2.77 & 0 & 71.18 & 58.95 & 66.97 & $\mathrm{~A} 11, \mathrm{~A} 40$ \\
\hline $\mathrm{A} 18$ & 0.566 & 0.747 & 20.97 & 33.98 & 0.757 & 0 & 12.08 & 34.80 & 53.86 & 87.35 & $\mathrm{~A} 15, \mathrm{~A} 40$ \\
\hline $\mathrm{A} 21$ & 0.412 & 0.521 & 54.01 & 35.62 & 0.791 & 13.01 & 0 & 60.48 & 33.56 & 56.81 & $\mathrm{~A} 11, \mathrm{~A} 17$ \\
\hline A22 & 0.684 & 0.774 & 25.85 & 15.97 & 0.883 & 2.83 & 4.33 & 6.00 & 0 & 80.84 & $\mathrm{~A} 13, \mathrm{~A} 40$ \\
\hline A23 & 0.561 & 0.768 & 32.68 & 4.30 & 0.730 & 22.85 & 0 & 75.10 & 46.00 & 91.05 & A40 \\
\hline $\mathrm{A} 25$ & 0.701 & 0.920 & 12.02 & 0 & 0.763 & 7.87 & 0 & 79.32 & 62.84 & 27.99 & A11 \\
\hline A26 & 0.386 & 0.765 & 20.06 & 30.42 & 0.504 & 0 & 18.91 & 212.09 & 272.77 & 2.56 & וחקיות \\
\hline A27 & 0.920 & 0.994 & 0 & 1.88 & 0.926 & 5.97 & 7.42 & 0 & 0 & 35.76 & $\begin{array}{c}\text { A2, A13, A17 } \\
\text { A40 }\end{array}$ \\
\hline A29 & 0.742 & 0.794 & 22.51 & 16.63 & 0.934 & 0 & 2.66 & 3.86 & 0 & 42.63 & $\begin{array}{c}\text { A13, A17, } \\
\text { A40 }\end{array}$ \\
\hline A30 & 0.299 & 0.535 & 43.60 & 52.30 & 0.558 & 0 & 57.65 & 126.59 & 159.47 & 31.39 & $\mathrm{~A} 11, \mathrm{~A} 17$ \\
\hline A32 & 0.389 & 0.439 & 59.38 & 49.59 & 0.886 & 4.26 & 0 & 13.54 & 0 & 77.89 & $\mathrm{~A} 11, \mathrm{~A} 17, \mathrm{~A} 4 \mathrm{C}$ \\
\hline A33 & 0.843 & 0.890 & 16.51 & 0 & 0.947 & 3.06 & 0 & 10.79 & 3.25 & 20.37 & $\begin{array}{c}\text { A13, A15, } \\
\text { A46 }\end{array}$ \\
\hline A34 & 0.461 & 0.865 & 0 & 40.55 & 0.533 & 0 & 34.71 & 119.61 & 259.64 & 28.62 & $\begin{array}{l}\text { A15, A17, } \\
\text { A40 }\end{array}$ \\
\hline A35 & 0.723 & 0.826 & 17.68 & 16.95 & 0.876 & 0 & 6.64 & 12.71 & 14.52 & 52.31 & $\mathrm{~A} 15, \mathrm{~A} 40$ \\
\hline A37 & 0.568 & 0.644 & 49.39 & 7.91 & 0.882 & 16.45 & 0 & 26.71 & 0 & 50.88 & $\mathrm{~A} 11, \mathrm{~A} 17, \mathrm{~A} 4 \mathrm{C}$ \\
\hline A38 & 0.606 & 0.710 & 36.20 & 14.71 & 0.854 & 12.15 & 4.95 & 13.70 & 0 & 89.60 & $\mathrm{~A} 11, \mathrm{~A} 40$ \\
\hline A39 & 0.638 & 0.816 & 15.24 & 24.59 & 0.781 & 19.59 & 49.59 & 0 & 0.63 & 54.81 & $\mathrm{~A} 11, \mathrm{~A} 40$ \\
\hline A41 & 0.358 & 0.503 & 43.80 & 61.48 & 0.713 & 2.11 & 0 & 44.02 & 136.35 & 49.98 & A11, A17 \\
\hline $\mathrm{A} 42$ & 0.604 & 0.713 & 28.77 & 28.55 & 0.848 & 6.70 & 28.64 & 2.94 & 0 & 46.85 & $\mathrm{~A} 11, \mathrm{~A} 40$ \\
\hline A44 & 0.620 & 0.778 & 30.88 & 4.71 & 0.797 & 3.98 & 0 & 74.85 & 52.18 & 9.34 & $\mathrm{~A} 13, \mathrm{~A} 17$ \\
\hline A45 & 0.640 & 0.879 & 12.34 & 11.51 & 0.727 & 36.12 & 59.35 & 3.71 & 0 & 80.29 & $\mathrm{~A} 13, \mathrm{~A} 40$ \\
\hline A47 & 0.476 & 0.530 & 55.31 & 30.34 & 0.897 & 5.10 & 0 & 22.23 & 0 & 53.01 & $\mathrm{~A} 11, \mathrm{~A} 17, \mathrm{~A} 4 \mathrm{C}$ \\
\hline A48 & 0.580 & 0.904 & 11.59 & 5.61 & 0.642 & 7.54 & 0 & 136.78 & 131.60 & 36.40 & $\mathrm{~A} 13, \mathrm{~A} 17$ \\
\hline A49 & 0.355 & 0.477 & 49.09 & 58.68 & 0.744 & 0 & 53.09 & 0 & 19.93 & 85.84 & $\begin{array}{c}\mathrm{A} 13, \mathrm{~A} 15 \\
\mathrm{~A} 17\end{array}$ \\
\hline
\end{tabular}




\begin{tabular}{|c|c|c|c|c|c|c|c|c|c|c|c|}
\hline \multirow{2}{*}{$\begin{array}{l}\text { Agent } \\
\text { ID }\end{array}$} & \multirow{2}{*}{$\rho^{*}$} & \multirow{2}{*}{$\rho_{I}^{*}$} & \multicolumn{2}{|c|}{$\begin{array}{l}\text { Excesses } \\
\text { (in \%) }\end{array}$} & \multirow{2}{*}{$\rho_{0}^{*}$} & \multicolumn{4}{|c|}{$\begin{array}{l}\text { Shortfalls } \\
\text { (in \%) }\end{array}$} & \multirow{2}{*}{$\begin{array}{c}\begin{array}{c}\text { Excess } \\
\text { (in \%) }\end{array} \\
\text { ICHT } \\
\end{array}$} & \multirow{2}{*}{$\begin{array}{l}\text { Reference } \\
\text { set }\end{array}$} \\
\hline & & & W & WT & & QACP & CS & NFCP & $C Q$ & & \\
\hline A50 & 0.553 & 0.619 & 37.29 & 39.85 & 0.894 & 0 & 12.78 & 0.57 & 0 & 55.93 & $\mathrm{~A} 11, \mathrm{~A} 17, \mathrm{~A} 40$ \\
\hline A52 & 0.817 & 0.873 & 19.01 & 0 & 0.936 & 9.42 & 0 & 10.35 & 0.57 & 28.97 & $\begin{array}{l}\text { A13, A17, } \\
\text { A46 }\end{array}$ \\
\hline A54 & 0.461 & 0.682 & 47.32 & 0.74 & 0.675 & 41.16 & 0 & 124.10 & 67.69 & 55.56 & $\mathrm{~A} 11, \mathrm{~A} 40$ \\
\hline A55 & 0.707 & 0.766 & 26.63 & 16.85 & 0.922 & 0 & 6.15 & 4.52 & 0 & 42.14 & $\mathrm{~A} 2, \mathrm{~A} 13, \mathrm{~A} 15$ \\
\hline \multicolumn{3}{|c|}{$\begin{array}{l}\text { Number of agents } \\
\text { with nonzero slack }\end{array}$} & 32 & 31 & & 26 & 20 & 32 & 21 & 36 & \\
\hline \multicolumn{3}{|c|}{ Average slack (in \%) } & 28.33 & 22.63 & & 8.57 & 15.16 & 44.14 & 46.93 & 49.90 & \\
\hline
\end{tabular}

\section{Fig. 1: Allocation of the agents: input vs. output efficiency}

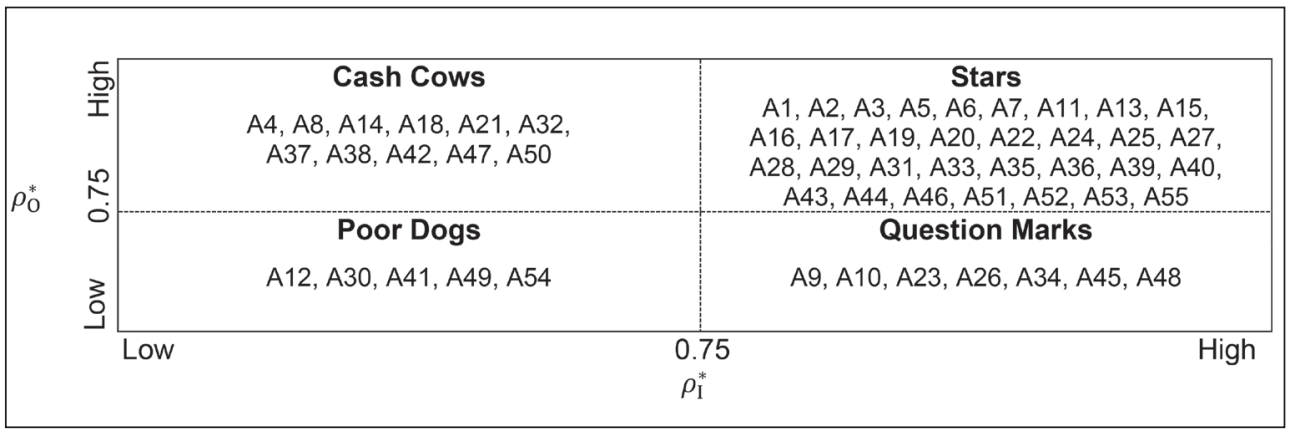

As stated previously, the WSBM-C model is relatively strict in terms of identifying the efficient agents. Its results can be viewed as the overall efficiency assessment in the long term. However, in the short term the influence of the external factors such as workload, stress and pressure may be present. To assess performance of call centre agents in the short term, the WSBM-V model is applied in the next step of the evaluation. Compared to WSBM-C, which identified 19 efficient agents, the WSBM-V model, which takes the impact of the external short-term efficiency-measuring factors into account, identified 26 efficient agents (see Tab. 4). The average efficiency score of 0.794 means that the average call centre agent shows almost $79.4 \%$ of the best agent's performance.
Also, in this model the least efficient agent is the agent $\mathrm{A} 30$ who achieves only $31.2 \%$ efficiency of the agents with the maximum efficiency.

To compare the efficiency of the agents in the short and long term, we followed the proposed DEAM framework. As Fig. 2 illustrates, with reference to the agents' joint performance evaluation (based on the WSBM-C and WSBM-V models with the same threshold value set for both of them at 0.75 ), the agents are divided into three groups: (1) Stars (both scores are higher than 0.75); (2) Question Marks (the WSBM-C score is less than or equal to 0.75 and the WSBM-V score is higher than 0.75) and Poor Dogs (both scores are less than or equal to 0.75 ). It should be noted that since $\rho_{\text {WSBM-C }}^{*} \leq \rho_{\text {WSBM-V }}^{*}$ for each DMU $i, i \in(1, \ldots, \mathrm{n})$ 


\section{Fig. 2: Allocation of the agents: CRS vs. VRS approach}

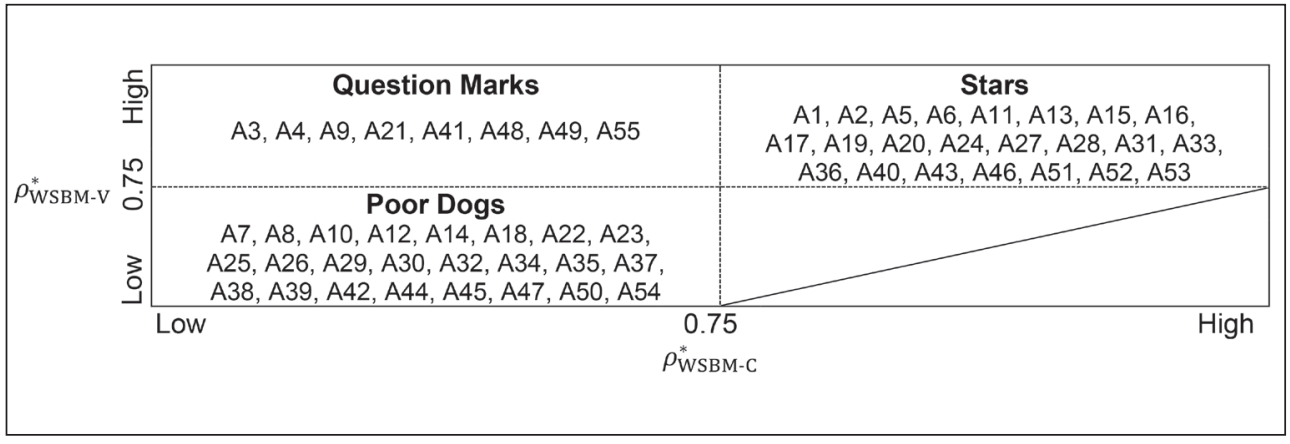

Source: own

and we consider the same threshold value for both models (0.75), no agent can be assigned to the lower right quadrant, i.e. Cash Cow group. Agents could be assigned to a given quadrant only if the threshold value for the WSBM-C model was less than the threshold value for the WSBM- $V$ model. As can be seen in Fig. 2, 23 agents (41.8\%) are in the Star group, 8 agents (14.5\%) in the Question Mark group, and 24 agents (43.6\%) in the Poor Dogs group. Star Group is the driving force of the call centre and should be motivated to maintain their excellent operational efficiency either by financial motivation (bonuses, recreational vouchers, etc), or by giving them more responsibilities and control over their work. The agents in the Poor Dogs group attain relatively low performance both in the short and long term. Their performance is unsatisfactory and it is up to the management to decide whether to motivate these agents to perform better, or to consider their dismissal. Finally, Question Marks group consists of those agents who achieve relatively high performance in the short-term, but their performance in the longterm is relatively low. The reason that could cause them to be ineffective in the long-term could be just the effect of the external factors such as work stress and exhaustion, or their temporary (health or social) indisposition. Whether it really is only a short-term deviation in their performance should be evaluated in a timeline, where their performance would be monitored over several time periods. Then it would be clear whether these agents tend to join Stars group, or rather Poor Dogs group.

\section{Conclusions}

Corporate performance measurement and assessment has long been in the centre of interest in corporate management. Companies are constantly compelled to find new ways of improving their performance in an effort to succeed in an increasingly competitive environment. Performance of a company is naturally determined by the performance of its employees. In general, the employees with knowledge and competence are the key assets that help the companies to retain their competitive advantage. Companies depend on singularity of their staff, as well as on the systems providing effective staff management in order to gain competitive advantage. Although staff performance assessment is one of the most sensitive areas of human resources management, it is an essential issue in this respect. The management have to specify which PA system is to be used, and then decide about the system implementation process.

The paper is devoted to the application of DEA in the PA, which is a relatively new perspective on the application of DEA in business practice. This area of DEA application can provide relevant and useful support for daily decision-making without often unavailable information about competitors in industry. The paper proposes a novel DEA approach for the relative performance evaluation of call centre agents, and specifies the steps of DEA application in the PA of call centre agents, including the design of possible inputs and outputs characterizing the activities of the 
evaluated agents, the design of the most appropriate DEA model for the analysed problem, and the method of presentation of the results obtained within the DEAM format. The proposed DEA approach was validated with fifty-five live agents working at the call centre of one of the largest telecommunications operators in the Slovak Republic. This empiric example showed how to select the appropriate DEA model with respect to the considered group of agents, and to the considered group of inputs and outputs characteristic for the agents' activity. For the purpose of the call centre agents' performance assessment, two non-oriented DEA models (WSBM-C model and WSBM-V model) were applied. Based on the results, the groups of agents were created in accordance with their achieved performance. Such presentation of the DEA model results provided satisfactory discrimination among the assessed agents' performance levels.

The proposed DEA approach to performance assessment of the call centre agents may help the call centre managers by: (i) providing information on the agents' performance based upon one composite efficiency indicator, (ii) identifying the agents with low or high performance, (iii) providing proposals for performance improvement of the inefficient agents, (iv) helping the managers identify strengths and weaknesses of the call centre as a whole, and ( $v$ ) allocating the agents into certain groups and thus making the managers' job easier, as they may choose the same policy for retaining or improving the performance of the agents in a given group. With the proposed approach and result analysis, the call centre managers are able to conduct proper analysis of the agents' performance on the grounds of their relative efficiency assessment.

It should be emphasized, however, that the results of the DEA models are, in general, very sensitive to the selection of the compared DMUs and considered inputs and outputs, as well as to the potential data errors (Ozbek et al., 2009). Seeing that DEA is a non-parametric method, it is impossible to assess the reliability of its results unlike, e.g. with the statistical methods. The choice of different inputs and outputs for call centre agents can provide different results. This point should not be seen as a defect of the proposed DEA approach because different combinations of inputs and outputs could reveal more weaknesses in achieving the agents' performance. Similarly, although the analysis set a lower bound on the inbound contact handle time uniformly (lower bound for each agent was set at 10 seconds), this limit can be set individually by assessing the actual inbound contact handle time for individual agents. Another option could be setting the lower bound for given input at the level of minimal observed value for the given input. It should also be pointed out that the proposed DEAM approach based on two-dimensional analysis creates a sufficient discrimination between the agents' performance. However, in the cases with insufficient discrimination capacity, the threshold values can be adjusted. In this paper, the same threshold value was set for all the efficiency scores. Another approach would be to set the threshold value either by considering the expert estimation of a manager, or at the level of the average efficiency score.

To conclude, relevance of the employees' performance assessment is naturally determined by meeting the assumption of bringing tangible conclusions, i.e. it should rather serve as means than as the purpose. The assessment results need to be documented and discussed with the employees so they can form the base for further personnel decisions, especially in the field of effective staff deployment, remuneration of the "efficient" employees by e.g. job promotion or pay rise, or motivation and dismissal of the "inefficient" employees. It is important to be aware that human factor activation is affected by a whole complex of factors, such as physical and mental abilities over which the HR manager has no direct control. However, another set of factors affecting the desire and will to work provides space for the application of various motivation tools, which can help the HR managers improve staff efficiency. As for the financial forms of motivation, various types of remuneration can be chosen, e.g. bonuses, commissions, or profit sharing. The non-financial forms of motivation mainly include optimal working conditions so as to improve quality of working life, or provision of various corporate social services (corporate training courses, meal allowances, vacations and other leisure time activities, health care, corporate loans, pre-school children's day care, etc).

Acknowledgement: The paper was supported by the grant scheme VEGA 1/0843/18 "Methodological aspects of DEA application on efficiency assessment of production units" of 
the Ministry of Education, Science, Research and Sport of the Slovak Republic.

\section{References}

Abuelwafa, H. (2014). Performance Evaluation in Call Centers: An Investigation into the Use of Analytics Tools (Master Thesis). St. Louis, MO: Washington University in St. Louis. Retrieved October 1, 2019, from https://scholar.cu.edu.eg/sites/default/ files/habuelwafa/files/thesis_final_version performance_evaluation_in_call_centers an_investegation_into_the_use_of_analytics_ tools.pdf

Anton, J. (1997). Call Center Management by the Numbers. Annapolis, MD: Purdue University Press/Call Center Press.

Anton, J. (2000). The Past, Present and Future of Customer Access Centres. International Journal of Service Industry Management, 11(2), 120-130. https://doi.org/10.1108/09564230010323534

Armentrout, D. R. (1986). Engineering Productivity Management and Performance Measurement. Journal of Management in Engineering, 2(3), 141-147. https://doi. org/10.1061/(ASCE)9742-597X(1986)2:3(141)

Arvey, R. D., \& Murphy, K. R. (1998). Performance Evaluation in Work Settings. Annual Review of Psychology, 49(1), 141-168. https://doi.org/10.1146/annurev.psych.49.1.141

Banker, R. D., Charnes, A., \& Cooper, W. W. (1984). Some Models for Estimating Technical Scale Inefficiencies in Data EnvelopmentAnalysis. Management Science, 30(9), 1078-1092. https:// doi.org/10.1287/mnsc.30.9.1078

Charnes, A., Cooper, W. W., Golany, B., Seiford, L. M., \& Stutz, J. (1985). Foundations of Data Envelopment Analysis for ParetoKoopmans Efficient Empirical Production Functions. Journal of Econometrics, 30(1-2), 91-127. https://doi.org/10.1016/0304-4076(85) 90133-2

Charnes, A., Cooper, W. W., \& Rhodes, E. (1978). Measuring the Efficiency of Decision Making Units. European Journal of Operational Research, 2(6), 429-444. https://doi.org/10.1016/0377-2217(78)90138-8

Cooper, W. W., Seiford, L. M., \& Tone, K. (2007). Data Envelopment Analysis: A Comprehensive Text with Models, Applications, References and DEA-Solver Software (2nd ed.). New York, NY: Springer Science and Business Media, Inc.

Dugelová, M., \& Strenitzerová, M. (2015). The Using of Data Envelopment Analysis in Human Resource Controlling. Procedia Economics and Finance, 26, 468-475. https://doi.org/10.1016/S2212-5671(15)00875-8

Farrell, M. J. (1957). The Measurement of Productive Efficiency. Journal of the Royal Statistical Society, 120(3), 253-290. https://doi. org/10.2307/2343100

Fielding, G. (2003). Taking Conversation Seriously: the Role of the Call Centre in the Organisation's Customer Contact Strategy. Interactive Marketing, 4(3), 257-266. https://doi.org/10.1057/palgrave.im.4340187

Hedley, B. (1976). A Fundamental Approach to Strategy Development. Long Range Planning, 9(6), 2-11. https://doi.org/10.1016/00246301(76)90005-4

Higgs, M., Plewnia, U., \& Ploch, J. (2005). Influence of Team Composition and Task Complexity on Team Performance. Team Performance Management, 11(7/8), 227-250. https://doi.org/10.1108/13527590510635134

Houlihan, M. (2002). Tensions and Variations in Call Centre Management Strategies. Human Resource Management Journal, 12(4), 67-85. https://doi.org/10.1111/j.1748-8583.2002. tb00078.x

Jafari, M., Bourouni, A., \& Amiri, R. H. (2009). A New Framework for Selection of the Best Performance Appraisal Method. European Journal of Social Sciences, 7(3), 92-100.

Katzenbach, J. R., \& Smith, D. K. (1993). The Wisdom of Teams: Creating the High Performance Organization. Boston, MA: Harvard Business School Press.

Kilduff, M., Angelmar, R., \& Mehra, A. (2000). Top Management Team Diversity and Firm Performance: Examining the Role of Cognitions. Organization Science, 11(1), 21-34. https://doi.org/10.1287/orsc.11.1.21.12569

Mahmudah, U., \& Lola, M. S. (2018). Robust Approach for Efficiency Measurement of Employee Performance under Profit Sharing System. Economic Journal of Emerging Markets, 10(1), 1-7. https://doi.org/10.20885/ejem.vol10.iss1.art1

Najar, A. V., Pooya, A., Zoeram, A. A., \& Emrouznejad, A. (2018). Assessing the Relative Performance of Nurses Using Data Envelopment Analysis Matrix (DEAM). Journal of Medical Systems, 42(7), 125. https://doi. org/10.1007/s10916-018-0974-x

Osman, I. H., Berbary, L. N., Sidani, Y., AlAyoubi, B., \& Emrouznejad, A. (2011). Data Envelopment Analysis Model for the Appraisal and Relative Performance Evaluation of Nurses 


\section{Marketing and Trade}

at an Intensive Care Unit. Journal of Medical Systems, 35(5), 1039-1062. https://doi. org/10.1007/s10916-010-9570-4

Ozbek, M. E., Garza, J. M., \& Triantis, K. (2009). Data Envelopment Analysis as a Decision-Making Tool for Transportation Professionals. Journal of Transportation engineering, 135(11), 822-831. https://doi. org/10.1061/(ASCE)TE.1943-5436.0000069

Robinson, G., \& Morley, C. (2006). Call Centre Management: Responsibilities and Performance. International Journal of Service Industry Management, 17(3), 284-300. https:// doi.org/10.1108/09564230610667122

Shirouyehzad, H., Lotfi, F. H., Aryanezhad, M. B., \& Dabestani, R. (2012). A Data Envelopment Analysis Approach for Measuring the Efficiency of Employees: A case study. South African Journal of Industrial Engineering, 23(1), 191-201. https://doi.org/10.7166/23-1-230
So, S. H. (2007). An Empirical Analysis on the Operational Efficiency of CRM Call Centers in Korea. International Journal of Computer Science and Network Security, 7(12), 171-178.

Tao, G. (2012). Multi-Department Employee Performance Evaluation Based on DEA Cross Efficiency. Journal of Emerging Trends in Economics and Management Sciences, 3(5), 553-558.

Tone, K. (2001). A Slacks-Based Measure of Efficiency in Data Envelopment Analysis. European Journal of Operational Research, 130(3), 498-509. https://doi.org/10.1016/ S0377-2217(99)00407-5

Zbranek, P. (2013). Data Envelopment Analysis as a Toll for Evaluation of Employees' Performance. Acta Oeconomica et Informatica, 16(1), 12-21. https://doi.org/10.15414/ raae.2013.16.01.12-21 